\title{
MATEO ALEMÁN Y TIMANTES, O LA EXPRESIÓN DEL INDECIBLE DOLOR DE LOS PADRES
}

En cierto punto de su deliciosa novelita de Ozmin y Daraja (Guzmán de Alfarache, I, i, 8), Mateo Alemán describe la gran preocupación de su heroína para saber del paradero de su amante, el cual ha sido separado de ella. Para ponderar la inquietud de Daraja por la suerte de Ozmín, Alemán echa mano de lo que era, evidentemente, una anécdota bien conocida en su época:

Que para pintar tristeza semejante, fuera poco el ardid que usó un pintor famoso en la muerte de una doncella, que, después de pintada muerta en su lugar, puso a la redonda a sus padres, hermanos, deudos, amigos, conocidos y criados de la casa, en la parte y con el sentimiento que a cada uno en su grado podía tocarle; mas, cuando llegó a los padres dejóles por acabar las caras, dando licencia que pintase cada uno semejante dolor según lo sintiese. Porque no hay palabras ni pincel que llegue a manifestar amor ni dolor de padres, sino solas algunas obras que de los gentiles habemos leído 1 .

La identificación de esta historieta se ha escapado a la diligencia de los anotadores y comentaristas del Guzmán. En sus respectivas ediciones, Samuel Gili y Gaya ${ }^{2}$ y Joaquín Saura Falomir ${ }^{3}$ pasan sobre este pasaje en silencio, mientras que Francisco Rico y Benito Brancaforte se limitan

1 Citamos por la última edición de Francisco Rico (Barcelona, 1983), pág. 216 (una reproducción fotográfica de la publicada originariamente en La novela picaresca española, I, Barcelona, 1966, con correcciones y adiciones, pero con la misma paginación en el texto).

2 Ed. Guzmán de Alfarache, 5 vols. (Madrid, 1942); cf. vol. I, págs. 207-208.

3 Ed. Guzmán, 2 vols. (Madrid, 1953); cf. vol. I, pág. 184. 
a aludir de una manera general a "Valerio Máximo, Facta et dicta memorabilia, V, vii, ix y x (y Celestina, XXI) ${ }^{4}$, donde se cuentan numerosos casos de padres que sufrieron grandemente a causa de sus hijos. Sin embargo, la relación del discreto artista que dejó de pintar lo indescriptible, era muy familiar a los lectores del Siglo de Oro. El pintor en cuestión era Timantes, un griego de principios del siglo IV antes de Jesucristo, un rival de Parrasio, y el creador del célebre cuadro de El sacrificio de Ifigenia (una copia del cual fue descubierta modernamente en Pompeya). Un excelente resumen de la anécdota que nos interesa lo da Fernando de Herrera al anotar la referencia de Garcilaso a Timantes en la égloga III, v. $120^{5}$. Allí se expresa Herrera de la siguiente forma:

De este pintor trata Quintiliano en el libro 2, cap. [13], y alaba mucho la tabla con que venció a Colotes Teyo ${ }^{6}$. Porque como pintase en el sacrificio de Ifigenia a Calcas triste, más triste a Ulises, y pusiese en Menelao toda la mayor tristeza que pudo alcanzar la fuerza de la arte, no hallando de qué modo debiese representar dignamente el vulto de su padre Agamenón, por haber ya gastado y consumido los afectos, le cubrió la cabeza con un velo, dejando en el ánimo de cada uno la consideración de aquella tristeza. Casi lo mismo refiere Tulio en el Perfecto orador 7 , y Valerio Máximo en el cap. [11] del lib. 88, y Plinio en el lib. 35, capitulo $[36]^{9}$...

4 Rico, loc. cit.; Brancaforte, ed. Guzmán, 2 vols. (Madrid, 1979), I, pág. 219; Brancaforte reproduce la nota de Rico. El cuentecillo está registrado en Malcolm Jerome Gray, An Index to «Guzmán de Alfarache» (New Brunswick, N. J., 1948), pág. 20, pero falta en Edmond Cros, Contribution à l'étude des sources de "Guzmán de Alfarache» (Montpellier, 1967).

5 Anotaciones, reproducidas en Garcilaso de la Vega y sus comentaristas, ed. Antonio Gallego Morell, 2." ed. (Madrid, 1972), pág. 572.

6 \&Vt fecit Timanthes... in ea tabula, qua Coloten Teium uicit. Nam cum in Iphigeniae immolatione pinxisset tristem Calchantem, tristiorem Vlixen, addidisset Menelao quem summum poterat ars efficere maerorem; consumptis adfectibus, non reperiens quo digne modo patris uultum posset exprimere, uelauit eius caput et suo cuique animo dedit aestimandum» (Quintiliano, Istitutiones oratoriae, ed. Jean Cousin, II, París, 1976, pág. 72).

7 « Si denique pictor ille vidit, cum immolanda Iphigenia tristis Calchas esset, tristior Ulixes, maereret Menelaus, obvolvendum caput Agamemnonis esse, quoniam summum illum luctum penicillo non posset imitari» (Cicerón, Orator, ed. H. M. Hubbell, Londres, 1971, pág. 360).

8 «Quid ille alter aeque nobilis pictor, luctuosum immolatae Iphigeniae sacrificium referens, cum Calchanta tristem, moestum Ulyssem, clamantem Ajacem, lamentantem Menelaum circa aram statuisset, caput Agamemnonis involvendo, nonne summi moeroris acerbitatem, arte exprimi non posse confessus est? Itaque pictura ejus, aruspicis, amicorum, \& fratris lacrymis madet: patris fletum spectantis affectui aestimandum reliquit. Atque ut ejusdem studii adjiciam exemplum, praecipuae artis pictor equum ab exercitatione venientem; modo non vivum labore industriae suae comprehenderat" (Valerio Máximo, Factorum dictorumque memorabilium, ed. Jacobo Perizonio y Antonio Schulting, Leiden, 1726, págs. 755-756).

9 «Nam Timanthis vel plurimum adfuit ingenii. Eius enim est Iphigenia oratorum 
Es de notar que Mateo Alemán ha modificado algunos de los rasgos básicos de la anécdota clásica, haciendo que se haya muerto Ifigenia, cambiando al solo padre (Agamenón) en padre y madre, y agregando "hermanos, deudos, amigos, conocidos y criados» en lugar de Calcas, Ulises y Menelao. Seguramente, Alemán escribía de memoria, sin consultar en el momento de redactar ninguno de los textos que hemos citado (aunque su versión se parece más a la de Valerio Máximo que a ninguna otra).

De paso, podemos observar que el afortunado cuadro de Timantes fue evocado por autores de otros países también. Para nombrar un solo ejemplo contemporáneo de Herrera y Alemán, recordaremos que Michel de Montaigne relata así la historia de Timantes en el segundo capítulo de sus Ensayos:

cet ancien peintre... ayant à représenter au sacrifice d'Iphigénie le deuil des assistants, selon les degrés de l'intérêt que chacun apportait à la mort de cette belle fille innocente, ayant épuisé les derniers efforts de son art, quand se vint au père de la fille, il le peignit le visage couvert, comme si nulle contenance ne pouvait représenter ce degré de deuil 10.

Total, se trata de un asunto ampliamente difundido a través de cuatro autores clásicos de los más leídos. Además, parece razonable suponer que Mateo Alemán volvería a conocer la anécdota en las Anotaciones del igualmente sevillano Herrera. Lo único que hacía falta para iluminar el presente pasaje del Guzmán era, pues, hacer memoria del nombre de Timantes, el cual se asociaba siempre en aquel siglo con la historia del padre cuyo dolor por su hija no podía ser captado ni por el mejor artista.

\section{DONALD MCGRADY}

Universidad de Virginia

\footnotetext{
laudibus celebrata, qua stante ad aras peritura cum maestos pinxisset omnes praecipueque patruum et tristitiae omnem imaginem consumpsisset, patris ipsius voltum velavit, quem digne non poterat ostendere» (Plinio, Historiae naturalis, ed. $\mathbf{H}$. Rackham, IX, Londres, 1968, pág. 314).

Las Anotaciones de Herrera datan de 1580; en 1598 Lope de Vega publicarfa su novela pastoril La Arcadia, y allí, al explicar en nota quién era Timantes, parece que resumió así la nota de Herrera: "Timantes, pintor famoso que, pintando el sacrificio de Ifigenia, no pudiendo significar el dolor de su padre respecto de los otros, le cubrió de un velo» (La Arcadia, ed. Edwin S. Morby, Madrid, 1975, página 181).

10 Montaigne, Essais, ed. Marcel Guibaud, I (París, 1962), pág. 52.

LXV, 3.0 - 4.0-10
} 